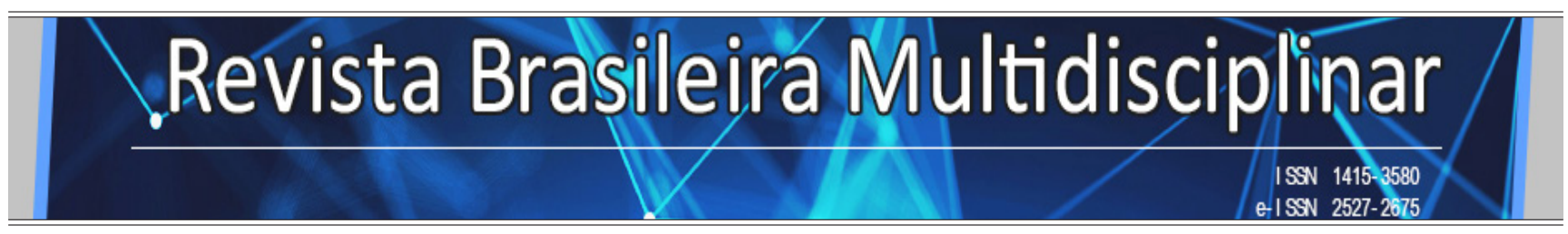

http://revistarebram.com/index.php/revistauniara

\title{
OBTENÇÃo de PATENTE E OS ASPECTOS DO REGIME DE COPROPRIEDADE
}

Amanda Gilvani Cordeiro Matias Correio*; Dandara Porto Pedreira ${ }^{* *}$; Anne Alice Nogueira Alves Costa ${ }^{* \star *}$; Luckas Tarik Cordeiro Sanatana $^{* * *}$; Victor Emanuell Cordeiro Santana ${ }^{* * *}$

${ }^{*}$ Docente na Universidade Federal da Bahia-UFBA.

${ }_{* *}^{*}$ Universidade Federal da Bahia-UFBA.

${ }^{* * *}$ Discente do curso de Direito - Faculdade Independente do Nordeste-FAINOR.

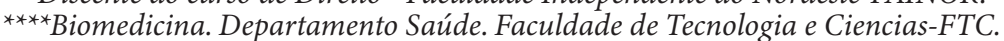

*Autor para correspondência e-mail: amathias.ufba@gmail.com

\section{Palavras-chave}

Patente

Diretrizes

Copropriedade

\section{KEYWORDS}

Patent

Guidelines

Co-Ownership

\section{RESUMO}

A crescente busca do sistema patentário para proteger invenções produzidas por organizações privadas e públicas, esboça um cenário atrelado ao atual desenvolvimento socioeconômico, baseado em avanços científicos tecnológicos que desempenham papel preponderante em transações produtivas de poder econômico mundial. O objetivo deste artigo é contextualizar sobre procedimentos para obtenção de patentes na jurisdição brasileira, com ênfase na copropriedade patentária. Realizou-se busca de manuscritos em bases científicas SciELO, Sciece direct e bancos de informações do INPI concernentes aos aspectos jurídicos. Os critérios pré-estabelecidos foram: janela temporal de 20102017, descritores vinculados a operadores booleanos e uso do State of the Art through Systematic Review (StArt) para identificar manuscritos em duplicidade. A análise adicional sobre os direitos relacionados à patente, pertencentes ao indivíduo ou organização, que registra a obtenção em regime de copropriedade são necessários. Cujo compartilhamento resguarda os direitos das partes, requerendo clareza das regras para evitar futuros litígios de lacunas contratuais.

\section{Abstract \\ Patent ObTainment AND ASPeCts OF CO-OWNership}

The growing search for patent system to protect inventions produced by private and public organizations outlines a scenario linked to current socioeconomic development, based on scientific technological advances that play a preponderant role in productive transactions of world economic power. The purpose of this article is to contextualize on procedures for obtaining patents in the Brazilian jurisdiction, with emphasis on the co-ownership patent. We searched for scientific manuscripts in scientific bases SciELO, Sciece direct and INPI information banks concerning legal aspects. The pre-established criteria were: time window 2010-2017, descriptors linked to Boolean operators and use of State of the Art through Systematic Review (StArt) to identify duplicate manuscripts. Further analysis of the patent-related rights belonging to the individual or organization that records co-ownership is required, whose sharing safeguards the rights of the parties, requiring clarity of the rules to avoid future disputes of contractual gaps. 


\section{INTRODUÇÃo}

Patente é um documento de concessão ou autorização pública concedido pelo Estado, o que no Brasil, os aspectos protocolares ocorrem através dos Instituto Nacional de Propriedade Intelectual (INPI). O registro de patente tem o objetivo de garantir ao titular o direito de exclusividade para explorar comercialmente a sua criação inovadora. A patente está diretamente relacionada a uma invenção tecnológica de um produto ou um processo com valor agregado mercadológico (SOARES; CORREIA, 2010; QUINTAL; TERRA, 2014).

O termo patente é proveniente do latim, de patens, de patentis, de petere, que significa clareza, ser evidente. Sendo a patente de invenção (PI) a que designa a carta ou o título de exclusividade ou privilégio concedido ao inventor titular do conhecimento. Assim nasce um título oficial de concessão explícito em uma carta-patente, como instrumento oficial, que concede autorização para exploração de uma tecnologia de produto ou processo decorrente do ato inventivo. Portanto, patente constitui um direito exclusivo que, estão resguardados pela Constituição Federativa de 1988 em seu art. 5², inciso XXIX e, infraconstitucional pela Lei da Propriedade Industrial $\mathrm{n}^{\circ}$ 9.279/1996, outrossim, mais precisamente em seu art. $6^{\circ}$ (CABELLO; PÓVOA, 2016; HEMMES, 2002).

No que se refere a titularidade da patente, versa o art. $6^{\circ}$ da Lei da Propriedade Industrial (LPI) que "Ao autor de invenção ou modelo de utilidade será assegurado o direito de obtenção da patente que garanta a propriedade, nas condições estabelecidas nesta Lei" e "Salvo prova em contrário, presume-se o requerente legitimado a obter o direito de exclusividade (BRASIL, 1996; HAMMES, 2002).

O direito de exclusividade face o regime de copropriedade pode ocasionar situações conflitantes e desmotivadoras em ambientes, como por exemplo, nas universidades e centro de pesquisas que visam resultados de $\mathrm{P} \& \mathrm{D}$. A patente em regime de copropriedade refere-se à existência de um ou mais titulares sobre o direito de sua exploração. Cujas prerrogativas estão descritas no direito brasileiro, notadamente com distinção de sua natureza especial da propriedade das invenções, exercida sobre bens imateriais. No mais, os princípios do direito civil relativos ao condomínio não têm rigorosa aplicação nesta matéria (BARBIERI 2000). Entretanto, já foi sinalizado por Barbosa (2008) e Fischer (2005) a viabilidade de aplicação do regime condomínio para resolver questões relacionadas a copropriedade de patente.

Para Fischer (2005), cada co-titular da patente deve concorrer com a manutenção da patente, com a liberdade de exploração do objeto patenteado, entretanto, deve obter autorização dos demais titulares em situação de licença a terceiros, prerrogativa que está condicionada às regras do Art. 633 do Código Civil de 1916. Tendo em vista o aumento de patentes em regime de copropriedade, é pertinente ampla compreensão da doutrina e a tendência da jurisprudência nestas condições. Assim, o objetivo desta pesquisa é descrever sobre a importância das patentes e contextualizar sobre o processo para obtenção de depósito de patentes no Brasil e, considerações sobre o regime de copropriedade patentária.

\section{Aspectos metodológicos da PESQuisa}

Trata-se de uma pesquisa de revisão sistematizada, com o intuito de sintetizar informações disponíveis em bancos de dados online sobre uma problemática específica, de forma objetiva, por meio do método científico e critérios predeterminados. Nesta revisão sistemática preconizou-se um método rigoroso de busca e de seleção de artigos científicos, seguido de avaliação da relevância, e síntese e interpretação a partir da leitura detalhada dos documentos selecionados. Dessa forma, foram pré-estabelecidos, como a pergunta norteadora do estudo, janela temporal e exclusão, além das estratégias de busca, análise e síntese das informações.

O critério de inclusão foi para as publicações disponíveis online em bancos de dados de publicação de pesquisas teórico-científicas, no idioma português, disponibilizadas em portal de periódicos, bases da Biblioteca Scielo, revistas eletrônicas, e leis dispostas em sites governamentais pertinentes, além das pu- 
blicações do Instituto Nacional de Propriedade Intelectual (INPI). Para coleta dos artigos foi realizada uma varredura, com os seguintes descritores: patente, propriedade industrial, depósito, copropriedade. Pergunta norteadora: Qual o tramite para obtenção de deposito de patente de acordo com o INPI e quais aspectos relevantes da patente em regime de copropriedade?

Assim, após a leitura e seleção com foco na pergunta norteadora, seguimos a organização das informações em forma de manuscrito. Os critérios de exclusão consistiram em informações que não atendessem aos critérios de inclusão, livres comunicações e livros. Totalizaram portanto, 21 documentos de publicação de sites oficiais e manuscritos pertinentes ao tema proposto nesta revisão, compreendendo uma janela temporal intermitente de 1996 a 2017.

\section{RESULTADOS E DISCUSSÃo}

\section{TIPOS E PRÉ-REQUisitos PARA PATENTEABILIDADE}

Sendo a patente um direito conferido pelo Estado, que garante ao seu titular a exclusividade da exploração da tecnologia, constitui uma contrapartida ao acesso do público ao conhecimento produzido e dos pontos essenciais e processuais da inventividade. Entretendo, a lei supracitada estabelece ao titular da patente um direito limitado, para sua exploração comercial em regime de exclusividade, sendo resguardado o segredo da tecnologia até que, vencidos os prazos, caia em domínio público (QUINTAL; TERRA, 2014).

A LPI-9279/96 que regulamenta direitos e obrigações da propriedade industrial, em seu art. $8^{\circ}$ discrimina que é patenteável o ato inventivo que atenda aos requisitos de novidade, atividade inventiva e que seja comerciável. As invenções passíveis de patente podem ser de duas formas: a) patentes de invenção (PI), b) patentes de modelo de utilidade (PMU) e, c) registro de desenho industrial entre outras modalidades, como as marcas que, não abordaremos neste texto. No Brasil é concedido, portanto, a PI que retrata o maior conteúdo tecnológico e as PMUs referentes ao aperfeiçoamento, dando com diferentes funcionalidades a dispositivos já existentes no mercado (SOARES; CORREIA, 2010; SPEZIALI, GUIMARÃES; SINISTERRA, 2012).

Quando um pedido de depósito é solicitado, o INPI confere ao depositante um número formado por letras e algarismos, sendo as duas primeiras letras maiúsculas alusivas à natureza da patente (PI ou PUM), seguido pelo número do pedido composto de sete dígitos. Na PI os dois primeiros algarismos referemse ao ano de depósito do pedido e, os números subsequentes são atribuídos em ordem cronológica de depósito no INPI, por exemplo, PI98212121 foi depositado em 1998. As patentes têm prazo de validade, sendo a PI válida por 20 anos e a PMU com validade de 15 anos (SOARES; CORREIA, 2010; MUELLER; PERUCCHI, 2014).

As patentes de invenção e modelo de utilidade são consideradas inéditas quando não compreendidos no estado da técnica, conforme art.11 da LPI. O estado da técnica deve abranger todas as publicações e outros meios públicos que precede da data de depósito do pedido, seja por descrição oral ou escrita por qualquer meio de divulgação nacional ou estrangeira (teses, dissertação, pôsteres, painéis, entrevistas, artigos científicos e outros). Neste sentido, a orientação é que os pesquisadores inventores não publiquem nenhum conteúdo antes de registrar o pedido de patente no órgão competente, visando retaliações futuras (ARAUJO et.al., 2010).

Notadamente, a solicitação de pedidos de patentes, tem aumentado no Brasil. Isso se deve a estreita relação existente entre Pesquisa e Desenvolvimento (P\&D), aliado ao desejo das organizações em desenvolver e explorar diversificados produtos e processos com fins econômicos. A indústria farmacêutica, desponta como grupo que apresenta índices recordes de lucratividade, mantendo constante patamar de depósito, seguida da indústria de eletrônicos e outros. O INPI divulgou o Boletim com estatísticas de 2016, sobre pedidos de depósitos de patentes, que totalizaram 2.567 numa perspectiva crescente. Também foi 
notória a solicitação de proteção de PIs feitas por 48 países, com destaque para os Estados Unidos (36\%), Brasil (15\%) e Alemanha (7\%). Já os depósitos de PMU residentes do Brasil foram responsáveis por 95\% no mesmo ano. Conforme a evolução dos depósitos demonstrados na figura 1, com atualização de série histórica dos depósitos de Pedidos para obtenção de PI e PMU (INPI, 2016).

Figura 1 - Evolução de pedidos de Depósito e exame de patentes acumulados 1998-2017.

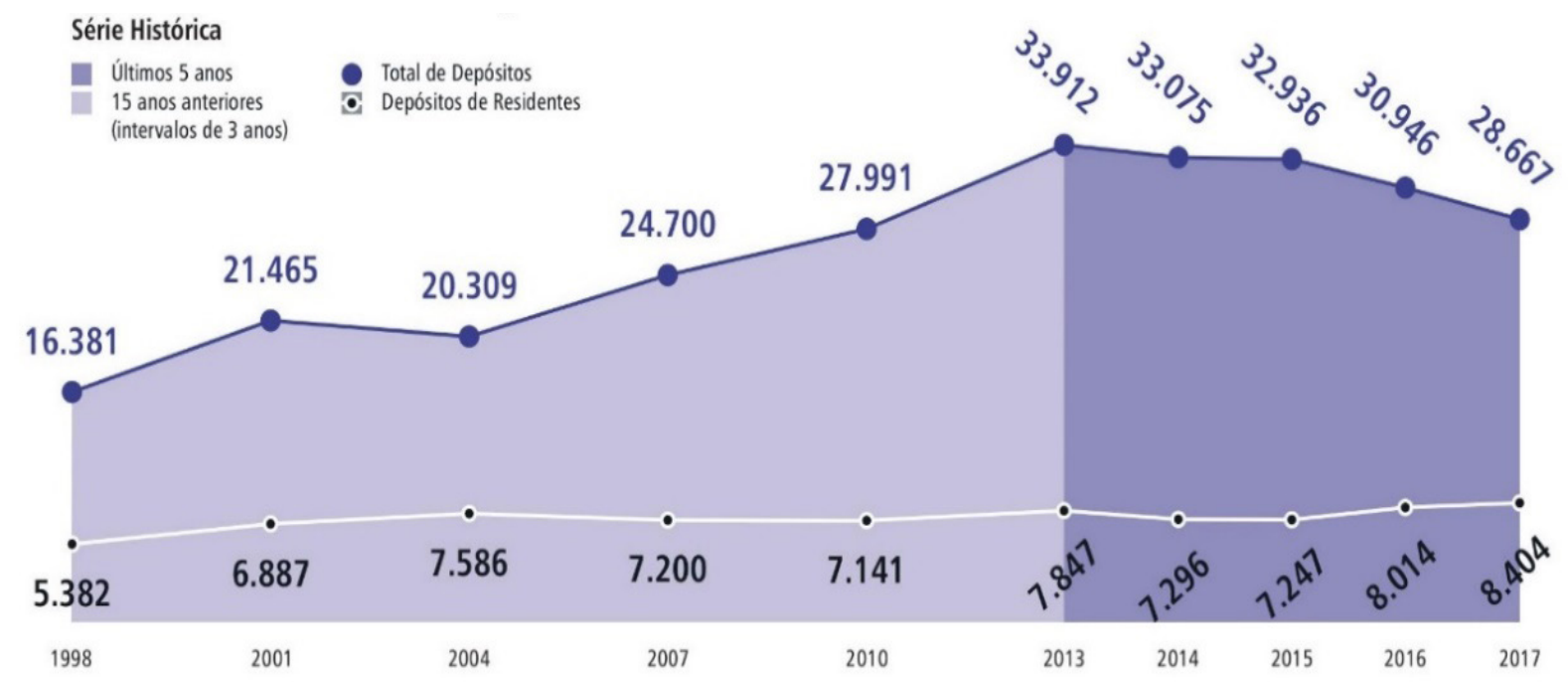

Fonte: INPI, 2017.

Verifica-se que houve consistente aumento de depósito desde 2004, mas somente em 2013 ocorreu maior percentual de pedidos, alcançando em 2017 mais de 8.400 registros. A evolução no número de exame de patente, deve-se principalmente às otimizações no fluxo e controle de processos no INPI, com as iniciativas de automação de procedimentos como os agendamentos automáticos de pareceres, documentos de publicação de pedidos etc. Tal cenário, por consequência, permitiu ampliar a expansão e a consolidação de políticas de incentivo à produtividade como o teletrabalho.

Vale destacar o aumento de pedidos para o registro de propriedade intelectiva no segmento de softwares no Brasil, que está em alta desde o ano de 2012. Provavelmente em decorrência da crescente utilização das diversas tecnologias com novos softwares, como os aplicativos de celular, computadores, dashboards e outros. Estes dispositivos são criados para suprir a demanda por produtos e serviços cada vez mais sofisticados nos segmentos sociais diversos (INPI, 2016).

Nessa pespectiva, o Brasil finalizou em 2017 com expressivo número de patentes, sendo o maior dos últimos 16 anos. Foi atingido o número de 6.250 patentes concedidas pelo INPI, de acordo com a Confederação Nacional de Industria brasileira, um crescimento real de 30,9\%. A figura 2, representa a evolução da concessão de patentes.

Obviamente, as reorganizações das atividades processuais de análises do INPI, aliada ao crescente pedido de obtenção de patentes recebidos, contribuíram significativamente para acelerar as concessões de patentes. $\mathrm{O}$ advento do sistema online para depósito de patentes, e-Patentes, tornou mais rápido e simples todo o processo administrativo no âmbito do INPI, desde 2014. Neste contexto, fica evidente a importância de reconhecer o passo-a-passo para solicitar o depósito e registro de patente, visto que, são essenciais para garantir o direito de exclusividade e a proteção contra a concorrência desleal. 
Figura 2 - Evolução do número de parentes concedidas pelo INPI nos últimos 16 anos.

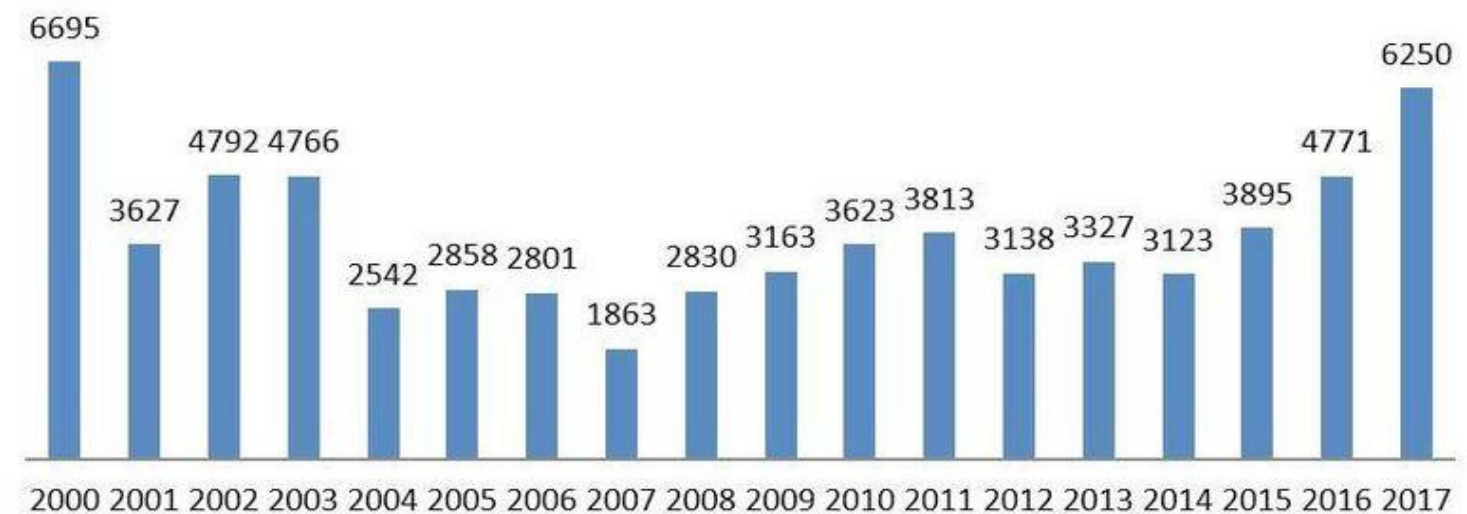

Fonte: CNI; INPI, 2017.

\section{Processo e trâmites para obter registro de patente}

Os trâmites para obtenção de patente não são complicados, mas requer atenção para compilação correta dos critérios compulsórios. Estes processos podem ser mais demorados do que o registro de uma marca, em alguns casos já demorou até 7 anos. Por isso é necessário que a solicitação esteja de acordo com a prerrogativas de patenteabilidade, decorrente da atividade inventiva e apresente aplicação industrial (INPI, 2017; CABELLO; PÓVOA, 2016; SILVA, SANTOS, MATIAS, 2014).

A patente é uma estratégia legal e a mais definitiva para proteção da propriedade intelectual, impedindo que o produto patenteado seja copiado ou comercializado por terceiros, sem a devida concessão legal. Este aparato de proteção da atividade intelectiva funciona como um vetor de aprendizagem tecnocientífica de um país, visto que abundância de patentes concedidas reflete a força da $\mathrm{P} \& \mathrm{D}$ e o grau de desenvolvimento socioeconômico. Assim é necessário o conhecimento mais robusto sobre o trâmite para depositar uma patente, reconhecer sua legislação e regras que regem a propriedade industrial. Além de incentivar práticas de invenções e inovações no âmbito científico biotecnológico e, demais segmentos empreendedores (CABELLO; PÓVOA, 2016; SILVA, SANTOS, MATIAS, 2014).

Portanto, registrar uma patente é uma forma preventiva contra a concorrência desleal, que garante a proteção sobre a invenção ou melhoramento de algum processo ou produto criado por qualquer cidadão, seja pessoa física ou jurídica. O registro visa resguardar a invenção contra o uso inapropriados por outras pessoas, organizações e até outros países, neste caso, a proteção se dá pelo Tratado de Cooperação em matéria de Patentes (PCT). Sendo que, a base legal interpretativa de que a invenção se trata de uma inovação tecnológica, respalda-se ao art.10 e art.18 da LPI no. 9.279/1996 que trata das exclusões para caracterizar patente e regula direitos e obrigações relativos à propriedade industrial (SILVA, SANTOS; MATIAS, 2014; QUINTAL; TERRA, 2014).

Vale ratificar que a ideia e conhecimento produzido, constitui parte do ato inventivo que é possível de ser pateteado. Porém, é necessário passar por um trâmite de submissão e análise, disponibilizado no Instituto Nacional de Propriedade Intelectual (INPI), como autarquia responsável pela gestão destes processos no Brasil. Destacando que, o depósito de patente é uma mera expectativa de direito, e não garante exclusividade, pro tempore, visto que ainda se encontra em processo de análise pela autarquia responsável, a garantia do monopólio de exploração é confirmada somente após expedição de carta-patente (SILVA; MATIAS, 2014; QUINTAL; TERRA, 2014). 
O processo que envolve o desenvolvimento de tecnologias pode ser compreendido em várias etapas. Considerando as startups, que são organizações em fase inicial que desenvolvem serviços e produtos inovadores, com potencial de acelerado desenvolvimento, iniciam no planejamento de projetos até condições de comercialização e ou geração de patentes. Nas universidades ou centros de pesquisas, por exemplo, as pesquisas em fase de laboratório possibilitam gerar resultados que podem entrar na fase de divulgação, através de artigos científicos, livros ou em eventos como congressos, simpósios e outros. Ou, ainda, podem ser protegidos diretamente através dos processos via INPI, cuja proteção de resultados científicos pode ocorrer por meio do know how ou da patente. A publicação de resultados da invenção, resultará em citações para os autores e, as patentes além das citações poderão atrair investidores nacionais, estrangeiros e, também, na possibilidade de ser licenciadas conforme prevê a Lei de Inovação nº 10.973/2004 e LPI (FERREIRA; GUIMARAES; CONTADOR, 2010; SPEZIALI GUIMARÃES; SINISTERRA, 2012).

Aspectos fundamentais a serem considerados durante o patenteamento, estabelecem que a primeira fase do depósito, consiste em realizar a busca prévia exaustiva em vários bancos de dados, na literatura técnica e livros pertinente, periódicos, notícias, artigos científicos e bancos de patentes. O objetivo desta busca a constatação da novidade real do invento que se pretende registrar. Publicações anteriores à tecnologia encontrada, são consideradas anterioridade, podem ser basilares na decisão sobre o critério da novidade ou a falta deste, na suposta invenção. No que se refere às patentes já depositadas, podem ser consultadas endereços de acesso gratuito conforme exemplos de algumas bases de dados, descritos na tabela 1.

Tabela 1 -Bases de dados para busca prévia de informações sobre patentes.

\begin{tabular}{|c|c|c|}
\hline Endereço eletrônico & Bases da Patente & Descrição dos critérios de busca \\
\hline http://www.inpi.gov.br & $\begin{array}{l}\text { Autarquia Brasil } \\
\text { INPI }\end{array}$ & $\begin{array}{l}\text { Busca prévia utiliza dados bibliográficos: } \\
\text { nomes, datas, título, key-words e outros sobre } \\
\text { possível depositante. }\end{array}$ \\
\hline http://www.uspto.gov & Autarquia Norte-americana & $\begin{array}{l}\text { Duas bases: documento digitalizado das } \\
\text { patentes concedidas e aquelas a partir de } \\
\text { 2001. Uso dados bibliográficos, título, resumo } \\
\text { e key-words. }\end{array}$ \\
\hline http://www.ep.espacenet.com & Escritorio Europeu EPO & $\begin{array}{l}\text { Busca e recuperação de patentes ut } \\
\text { lizando dados bibliográficos e keywords. }\end{array}$ \\
\hline http://www.fda.gov & Food Drugs Americans-FDA & $\begin{array}{l}\text { Banco de patentes americanas referente a } \\
\text { medicamentos. Busca pelo nome princípio } \\
\text { ativo e marca. }\end{array}$ \\
\hline https://scifinder.cas.org/ & $\begin{array}{l}\text { SciFinder Scholar } \\
\text { Chemical Abstract Service CAS }\end{array}$ & $\begin{array}{l}\text { SciFinder é uma ferramenta de consulta } \\
\text { de pesquisadores. Inclui informações de } \\
\text { Universidades e centros de pesquisas no } \\
\text { Brasil. Busca: indexadores, título, nomes e } \\
\text { resumos. }\end{array}$ \\
\hline http://www.wipo.int/pct & Patent Cooperation Treat -PCT & $\begin{array}{l}\text { PCT - tratado multilateral para requerer } \\
\text { proteção patentária simultânea em países } \\
\text { signatários. Busca pelo título, nomes, resumo } \\
\text { e key-words }\end{array}$ \\
\hline
\end{tabular}

Fonte: Elaborado pelos autores, 2018. 
Outros bancos de dados estão disponíveis nos escritórios de patentes, o da China no endereço: http:// english.sipo.gov.cn/, Canadian Intellectual Property Office (CIPO) http://cipo.gc.ca/ e, demais bancos de acesso gratuitos como: http://www.patentlens.net/, http://www.freepatentsonline.com e http:// www.patentstorm.us/, os quais recomenda-se que sejam de consulta mandatória, visto que, além de informações sobre depósitos, disponibilizam importantes elementos a respeito da propriedade industrial, como a transferência de tecnologia, cursos on-line e outros. Algumas universidades através do portal de periódicos da Coordenação de Aperfeiçoamento de Pessoal de Nível Superior (CAPES), disponibiliza acesso pelo Derwent Innovation Index: www.isiknowledge.com, bastante úteis, assim como os softwares de busca Scifinder e Reaxys (SPEZIALI, GUIMARÃES; SINISTERRA, 2012; FERREIRA; GUIMARAES, CONTADOR, 2010).

A busca prévia pode ser realizada pelo próprio interessado nos bancos de dados e, também pode solicitar a "busca isolada", cuja pesquisa é realizada por técnicos do INPI, mediante o pagamento de uma taxa. De a acordo com contextualização preconizadas por Araújo et.al., (2010); Spezialli, Guimarães \& Siniesterra (2012), também o manual do INPI, seguem na descrição das etapas para elaboração de um depósito para obtenção de patente, tendo em vista que o conteúdo técnico deve conter:

A) um relatório descritivo da PI ou PMU, apontando de forma objetiva o problema existente no estado da técnica e a solução proposta, ressaltando a novidade descrita de maneira reprodutível, conforme prerrogativas do art.24/LPI.

B) As reivindicações - fundamentadas no relatório descritivo, deverão definir, de forma clara e objetiva a matéria objeto da proteção, segundo art.25/LPI. É um requisito de extrema importância na elaboração do pedido, pois definem e delimitam os direitos do autor(es) balizados no art.41/LPI.

C) Listagem de sequência e desenhos (se for o caso) - figuras, desenhos, fluxogramas fornecem informações adicionais para melhor compreensão da invenção e, devem estar relacionadas no relatório descritivo, não deverão conter textos explicativos, exceto quando absolutamente indispensáveis. Quando o pedido contiver sequências de nucleotídeos e/ou de aminoácidos no processo descritivo, deverá representálas em Listagem de Sequências, para possibilitar aferição da suficiência descritiva conforme Art. 24/LPI e Resolução INPI/PR nº81/2013.

D) Resumo - descrição sucinta da matéria em questão ressaltando claramente o invento pleiteado, contendo 50-200 palavras limitando-se a 20 linhas de texto, sem mencionar o mérito ou valor da invenção ou modelo.

E) Comprovante do pagamento da retribuição relativa ao depósito.

F) Formulários - o Ato Normativo no 130/1997 e Resolução 135/2006, dispõem sobre os formulários para o requerimento de depósito de pedido de patente e certificado de adição de invenção, cujo modelo 1.01, é obtido na página do INPI.

G) Onde e como depositar o Pedido de Patente no Brasil - entregar os documentos no próprio escritório do INPI ou, através de envio postal (à Diretoria de Patentes - DIRPA/CGPROP) - Praça Mauá nº, Centro, CEP: 20081-240, com a indicação do código DVP. Demais especificações para redação e formatação do pedido encontram-se no Ato Normativo nº127, item 15.3.

Segue uma compilação de esclarecimentos referentes às etapas no contexto processual administrativo, conforme quadro 1.

Referente ao período de sigilo, cujo prazo é de dezoito meses a partir da data do depósito do pedido de patente. Neste período o processo fica sob guarda do INPI, sem qualquer divulgação, sendo que o prazo máximo é de 36 (trinta e seis) meses, quando ocorre a publicação na Revista da Propriedade Industrial(RPI) que, pode ser abreviada pelo Exame técnico antecipado (INPI, 2016). 
Quadro 1 - Etapas do processo administrativo para obtenção de patente e orientações práticas.

\begin{tabular}{|c|c|}
\hline Etapas do processo administrativo & Orientações práticas \\
\hline $\begin{array}{l}1^{\circ} \text { Pesquisa: consulta para verificar se há algum registro parecido } \\
\text { ou igual ao que se pretende patetear. }\end{array}$ & $\begin{array}{l}\text { Consultar bases de patentes do INPI, revistas especializadas } \\
\text { e outros. }\end{array}$ \\
\hline $\begin{array}{l}2^{\circ} \text { Peticionamento: processo administrativo, com detalhes do } \\
\text { invento (descrição) com data e hora da elaboração documental } \\
\text { (escritórios de consultorias) }\end{array}$ & $\begin{array}{l}\text { Ato Normativo - Escrever o pedido da patente: relatório } \\
\text { descritivo, estado da técnica, a solução encontrada e as } \\
\text { reivindicações do que se pretende proteger. }\end{array}$ \\
\hline $\begin{array}{l}3^{\circ} \text { Depositar o pedido: do site do INPI imprimir a GRU e pagar } \\
\text { taxa de análise do depósito. Solicitar pedido do exame e entrar } \\
\text { com todos os documentos necessários acessar o e-Patentes }\end{array}$ & $\begin{array}{l}\text { O pedido permanece em sigilo por } 18 \text { meses. Período } \\
\text { suposto para negociações pelo depositante. Após solicitação } \\
\text { do exame, aguardar na fila das análises do INPI }\end{array}$ \\
\hline $\begin{array}{l}4^{\circ} \text { Publicação: após } 20 \text { a } 40 \text { dias do protocolo, ocorrerá } \\
\text { publicação oficial na Revista da Propriedade Industrial - RPI/ } \\
\text { INPI }\end{array}$ & $\begin{array}{l}\text { Cadastrar no sistema push do INPI e verificar semanalmente } \\
\text { na RPI - usar o código de registro recebido. }\end{array}$ \\
\hline $\begin{array}{l}5^{\circ} \text { Exame de Mérito: INPI examina o pedido, pode demorar } 2 \\
\text { anos. Neste intervalo, podem ser solicitados documentos de } \\
\text { esclarecimentos - vigora } 60 \text { dias }\end{array}$ & $\begin{array}{l}\text { A patente será concedida após deferimento final do INPI } \\
\text { e, pagamento da retribuição de carta-patente até } 60 \text { dias. }\end{array}$ \\
\hline $\begin{array}{l}6^{\circ} \text { Obrigaçóes: de posse da carta-patente o titular(es) deve pagar } \\
\text { anuidade a partir do terceiro ano do pedido. }\end{array}$ & $\begin{array}{l}\text { Anuidades deverão ser pagas durante a vigência da patente } \\
20 \text { anos (PI), } 15 \text { anos para modelo de utilidade. }\end{array}$ \\
\hline
\end{tabular}

Fonte: Elaborado pelos autores, 2018.

Os valores cobrados em taxas e retribuições para pessoa física e jurídica estão dispostos no próprio site do INPI, que emitirá uma guia de recolhimento da união (GRU) de pagamento conforme a modalidade solicitada. Destacamos que o depósito de documentos de patente no INPI pode ser feito eletronicamente pelo Sistema e-Patentes/Depósito (e-depósito), desde o ano 2013, com a utilização de Certificado Digital, em que o interessando pode fazer o download do programa e usá-lo off-line para preenchimento dos formulários de requerimento e inclusão dos documentos e, o sistema recebe a documentação e automaticamente, emitindo recibo ao fim do procedimento. O quadro 2 sintetiza os prazos de procedimentos aqui dissertados.

Algumas condições ganharam prioridade no exame dos pedidos de patente, como por exemplo, o depositante que tenha idade igual ou superior a 60 anos; objeto do pedido que esteja sendo reproduzido por terceiros sem a sua autorização ou, caso a concessão da patente seja condição vinculada para obter recursos de agências de fomento; instituições de créditos oficiais; e, para a exploração do respectivo produto ou processo previsto na Resolução INPI nº151/2015. Em função da necessidade de acelerar os pedidos de patentes estratégicas ligadas ao Sistema Único de Saúde (SUS), o INPI oferece exame prioritário relacionados a produtos, processos farmacêuticos, equipamentos e materiais relacionados à saúde pública conforme prevê Resolução INPI/PR n080/ 2013 (INPI, 2016; BRASIL, 1996).

Tendo expirado o período de exclusividade concedido pelo Estado sobre o objeto de patente, tal conhecimento inventivo cairá em domínio público e poderá ser livremente utilizado por terceiros, podendo ser fabricado ou apropriado por quem desejar (SPEZIALLI, GUIMARÃES; SINISTERRA, 2012; INPI, 2016). 
Quadro 2 - Síntese dos procedimentos e etapas do pedido de depósito de patentes

\section{Após 60 dia da publicação}

\begin{tabular}{clll} 
Período de Sigilo & \multicolumn{1}{c}{$\begin{array}{c}\text { Prazo } \\
\text { I8 meses }\end{array}$} & $\begin{array}{c}\text { Deferido: } 60 \text { dias } \\
\text { para pagar taxas }\end{array}$ \\
Depósito & $\begin{array}{l}\text { Publicação } \\
\text { do pedido }\end{array}$ & $\begin{array}{c}\text { Exame do } \\
\text { do pedido }\end{array}$ & Expedida Carta-patente \\
Patente & na RPI & &
\end{tabular}

Fonte: Elaborado pelos autores, 2018.

\section{Patente em regime de copropriedade análoga ao código civil}

O aparato legal sobre a propriedade inventiva no Brasil, não prevê elucidações diretivas claras sobre questões de copropriedade de patente. Apenas o $\$ 3^{\circ}$ no art. $6^{\circ}$ da LPI, define que a patente pode ser solicitada por mais de um titular e ou inventores. Entretanto, por se tratar de situação complexa com possibilidades conflituosas por lacunas existentes, requer outras disposições regulamentares relacionados em assunto de propriedade. Assim o código civil tem servido de base suplementar interpretativa às questões emergentes. Barbosa (2008) esclarece que o processo integrativo do sistema jurídico (jus abhorret vacuum) que a insuficiência normativa em determinado setor da juridicidade é suprida por normas de maior compatibilidade, considerando o conceito de propriedade como direito absoluto, exclusivo e patrimonial.

Portanto, diante a incipiência de diretrizes específicas e, quando as regras aplicáveis à matéria tangível decorrem de atividade humana, torna o direito real como modelo quando aplicado a direito de propriedade industrial, visto que, o direito à patente diverge de qualquer outro tipo de propriedade. Desta maneira, regras sobre copropriedade requer preceitos interpretativos com especificidade. (BARBOSA, 2008; DIAS; PORTO, 2013).

Quando ocorrem situações conflituosas relacionadas a copropriedade, como a responsabilidade pelo processo administrativo na obtenção da patente, a exploração do objeto pateteado por um dos coproprietários isoladamente, casos de licenciamento ou transferência de uma das partes compartilhadas, são requeridas analogias vinculadas ao Código Civil. Principalmente pela similitude das linhas relativas aos direitos e deveres de propriedade de todos os titulares. Os coproprietários são igualmente responsáveis por custos de obtenção e manutenção de patente e de seus derivados. No que se refere à exploração do objeto patenteado, é doutrinada em consenso com o atual Código Civil em seu art.1.314. Esta prerrogativa baliza que, cada coproprietário detém o direito de explorar o objeto patenteado sem a necessidade de obtenção formal de autorização dos demais. Entretanto, para casos de cessão de licença a terceiros, a doutrina em consonância com a legislação vigente, respalda a necessidade da ciência e autorização dos coproprietários (DANNEMAN, 2002; DINIZ, 2002; DIAS; PORTO, 2013).

Por fim, o proprietário da patente será o indivíduo ou organização que a depositou e assim, constará concedida, que pode ser o próprio inventor, ou a organização pública ou privada. Em casos de resultados de pesquisa universitária, a mesma é acatada como a titular de toda criação inovadora desenvolvida pelos acadêmicos, pesquisadores ou técnicos, quando se utilizam recursos e equipamentos de suas instalações. Sempre resguardando os direitos de órgãos financiadores ou fomento, sendo, portanto, compartilhados na forma de copropriedade patentária. Contudo, a obtenção e questões sobre a patente em regime de copropriedade, requer que tais regras contratuais sejam claras para evitar futuros problemas decorrentes de lacunas nos acordos estabelecidos (DANNEMAN, 2002; DINIZ 2002; DIAS; PORTO, 2013). 
É de fundamental importância ratificar que, a patente cujo regime é compartilhado ou de copropriedade, são aquelas depositadas por mais de um titular, subsidiariamente regidas pelo novo Código Civil, Lei 10.406/2002, parte III, cap. VI, referente a condomínios, naquilo que a LPI não prevê. A disposição dispõe que cada coproprietário deve concorrer com as manutenções obrigatórias durante a vigência da patente, resguardados também os direitos de explorar livremente o objeto de patente. E, ainda, deve obter autorização dos compartilhados dos demais titulares no caso de licença a terceiros (BARBOSA, 2002, BRASIL, 2002; DIAS; PORTO 2013).

De acordo com os mesmos autores, tais prerrogativas estão respaldadas no art. $6^{\circ}, \$ 3^{\circ}$ da LPI N. ${ }^{0}$ 9.279/96 da seguinte forma: "Quando se tratar de invenção ou de modelo de utilidade realizado conjuntamente por duas ou mais pessoas, a patente poderá ser requerida por todas ou qualquer delas, mediante nomeação e qualificação das demais, para ressalva dos respectivos direitos. ". Mediante algumas situações indesejáveis não previstas no regime co-propriedade, torna-se pertinente a apuração da doutrina e tendência da jurisprudência aplicável.

\section{CONSIDERAÇões FINAIS}

A presente pesquisa buscou esclarecer a importância e conceitos relativos ao depósito para obtenção de Patente de Invenção e Modelo de Utilidade, além de descrever suscintamente fases processuais para registro junto ao INPI, contextualizados a partir da LPI vigente no Brasil. Tais elucidações podem contribuir e subsidiar processos protocolares de obtenção do registro de patente, com ênfase no regime de copropriedade. Para tanto, vinculou-se a discussão de tópicos relevantes, como o regime de copropriedade, mediante compartilhamento entre titulares de mesmo direito sobre o objeto patenteado.

Embora existam questões ainda incipientes quanto ao regime de copropriedade de patente - que já foram estudadas pela doutrina, bem apontadas por Frank Fischer -, neste manuscrito foram revisitados temas fundamenteis no que tange ao regulamento da PI neste regime. Procurou-se esclarecer conceitos fundamentais e questões sobre a titularidade da patente de invenção, desenvolvidas durante as atividades universitárias, em organizações de trabalho, em instituições de pesquisa e outras. O direito a patente é pertencente à organização onde foram desenvolvidos os processos inventivos, sempre considerando os diretos dos titulares e do inventor. Ressaltado que é de imprescindível que sejam convencionados nos contratos, como se dará o compartilhamento dos direitos dos titulares.

Vale advertir que a questão da copropriedade de patente constitui-se em matéria de extremada importância na gestão da PI, ao delimitar os direitos e obrigações dos titulares, de acordo com a política e gestão organizacional, antes da submissão do pedido da patente ao INPI.

Em adição, fica sinalizado o desafio das universidades públicas brasileiras e outras organizações de pesquisa, para a adoção de procedimentos legais adequados em seus contratos em regime de copropriedade, que resguardem os direitos dos autores, de modo a incentivar a inovação compartilhada.

Em face ao exposto, pretendeu-se encorajar a expressão de pontos de vista publicados, tendo as leis pertinentes como cenário interpretativo, para clarificar sobre aspectos de proteção da inovação e direitos autorais. A doutrina dos equivalentes elementos que envolvem o patenteamento para que seja garantido o tratamento justo aos proprietários comuns em termos de propriedade industrial.

\section{REFERÊNCIAS}

ARAÚJO, E.F. et.al. Propriedade Intelectual: proteção e gestão estratégica do conhecimento. Revista Brasileira de Zootecnia, Viçosa, v. 39 (Suppl.), n.1, p.02-10, jul. 2010.

BARBIERI J.C. As invenções realizadas por empregados no Brasil: uma análise da legislação atual e 
propostas de mudanças. RAP. R. Janeiro. v.1, p. 7,2b. jan.-fev. 2000

BARBOSA, D. B. O Inventor e o Titular da Patente de Invenção. Rio de Janeiro. Lumen Juris, 2008. (Col. Propriedade Intelectual). Disponível http://denisbarbosa.addr.com/113.rtf.

BRASIL. Lei n. 10.406, de10 de jan. de 2002. Institui o Código Civil. Disponível em: Acesso em: 22 de mar. de 2018. Disponível em: http://www.planalto.gov.br/ccivil_03/Leis/2002/110406.htm

BRASIL. Lei número 9.279, 14 de maio de 1996. Regula os Direitos Relativos à Propriedade Industrial. Disponível: http://www.planalto.gov.br/ccivil_03/leis/19279.htm.

CABELLO A.F.; PÓVOA L.M.C. Análise econômica da primeira Lei de Patentes Revista Brasileira de Estudos Econômicos, São Paulo, v.46, n.4, p.879-907, dez. 2016.

DANNEMANN, SIEMSEN, BIGLER; IPANEMA MOREIRA. Propriedade Intelectual no Brasil. Rio de Janeiro, PVDI Design, p.555-556, 2000. Disponível em: https://www.dannemann.com.br/

DIAS, A. A.; PORTO, G.S. Gestão de transferência de tecnologia inova Unicamp. Rev. adm. Contemp, Curitiba, v. 17, n.3, p.263-284, jun. 2013.

DIAS, J. C. V. Aspectos legais relativos à co-titularidade de invenções: o código civil e a Lei de Inovação em perspectiva. Revista Semestral de Direito Empresarial, v. 3, n.04, p.95-125, 2008.

DINIZ, M. H. Código civil anotado. Atual de acordo com o novo Código civil. (Lei n. 10.406/2002). Código civil Brasileiro. 8. ed. São Paulo:Saraiva, 2002.

FERREIRA, A.A., GUIMARÃES E.R., CONTADOR J.C. Patente como instrumento competitivo e como fonte de informação tecnológica. Gest. Prod., São Carlos, v. 16, n.2, p.209-221, 2010.

FISCHER F. O regime de co-propriedade em patentes. Revista da Associação Brasileira da Propriedade Intelectual, ABPI, n. 76, Maio/jun. 2005.

HAMMES, B.J. O Direito de propriedade intelectual. 3.ed. São Leopoldo :Unisinos, 2002.

INPI- INSTITUTO NACIONAL DA PROPRIEDADE INDUSTRIAL. Inventando o futuro: uma introdução às patentes para as pequenas e médias empresas. Cartilha de patentes. Rio de Janeiro, 2015. Disponível: http://www.inpi.gov.br/sobre/arquivos/03_cartilhapatentes.pdf.

INPI-INSTITUTO NACIONAL DA PROPRIEDADE INDUSTRIAL. Universidades Brasileiras - Utilização do Sistema de Patentes. 2007, p.41-47 Disponível em: http://www.inpi.gov.br/menu-servicos/ informacao/arquivos/universidades_brasileiras.pdf. Acesso em: 29 abr. 2016.

JANNUZZI, A. H. 1.; VASCONCELLOS, A.G. Quanto custa o atraso na concessão de patentes de medicamentos para a saúde no Brasil? Cad. Saúde Pública, v.33, n.8, p.e00206516, 2017.

MUELLER, S.P.M; PERUCCHI, V. Universidades e a produção de patentes: tópicos de interesse para o 
Obtenção de patente e os aspectos do regime...

estudioso da informação tecnológica. Perspectivas em Ciência da Informação, v.19, n.2, p.15-36, 2014. QUINTAL, R.S.;TERRA, B.R.C.S.; SILVA, R. Políticas organizacionais de ciência, tecnologia e inovação e gestão da propriedade industrial: uma análise comparativa em Instituições de Pesquisa. Gestão \& Produção, v.21, n.4, p.760-780, dez., 2014.

SILVA, M.S, SANTOS; F.P.C; MATIAS, A.G.C. Biotecnologia e o sistema patentário brasileiro: desenvolvimento e inovação tecnológica. Resiget, v. 4 n.1, p.054-063, 2014.

SOARES, J. M.; CORREA, M.C.D.V. Como pesquisar o perfil patentário de um fármaco: o caso Efavirenz. Química Nova, v.33, n.5, p.1216-1219, 2010.

SPEZIALI, M. G., GUIMARÃES, P.P.G.; SINISTERRA, R. D. Desmistificando a proteção por patentes nas universidades. Química Nova, v.35, n.8, p.1700-1705, 2012. 